\title{
Evaluation of positive expiratory pressure as an adjunct to chest physiotherapy in the treatment of cystic fibrosis
}

\author{
J L HOFMEYR, B A WEBBER, M E HODSON \\ From Brompton Hospital, London
}

\begin{abstract}
It has been suggested that positive expiratory pressure may assist the clearance of bronchial secretions in the treatment of cystic fibrosis. It has been compared with currently used postural drainage techniques. Three treatment regimens were compared in 18 patients with cystic fibrosis. Treatment A consisted of breathing exercises emphasising inspiration, interspersed with the forced expiration technique in gravity assisted positions; treatment B comprised breathing exercises with positive expiratory pressure alternating with the forced expiration technique in the same gravity assisted positions; and treatment $C$ comprised breathing exercises with positive expiratory pressure and the forced expiration technique in the sitting position. During treatment $A$ a significantly greater quantity of sputum was produced than during treatments $B$ and $C(p<0.025$ and $p<0.001$ respectively). Treatment $B$ produced more sputum than treatment $C(p<0.005)$. There were no significant differences in arterial oxygen saturation, $\mathrm{FEV}_{1}$ or forced vital capacity. Most adolescent and adult patients are able to carry out their treatment independently using gravity assisted positions, breathing exercises emphasising inspiration, and the forced expiration technique. Sputum clearance was less effective when positive expiratory pressure was included in the treatment regimen.
\end{abstract}

Positive expiratory pressure is used to assist clearance of bronchial secretions in some patients with cystic fibrosis. ${ }^{1}$ It has been suggested that it may increase the sputum yield by its effect on peripheral airways and collateral channels. Treatment using this technique does not include gravity to assist drainage of secretions but is carried out in the sitting position. One of the advantages claimed for this treatment is that it gives independence to this group of patients, as it can be carried out without an assistant.

Many patients with cystic fibrosis, however, have been treating themselves independently since the introduction of the more active form of postural drainage incorporating the forced expiration technique described by Pryor et al. ${ }^{23}$ Treatment has not included positive expiratory pressure, but deep breathing exercises have been used to mobilise secretions.

It is important to find physiotherapy techniques which are both effective and less time consuming

Address for reprint requests: Miss B A Webber, Physiotherapy Department, Brompton Hospital, London SW3 6HP.

Accepted 30 June 1986 while giving the patient independence. We have therefore compared these two methods of treatment and a combination of the two.

\section{Patients and methods}

Eighteen patients (12 male, six female) with cystic fibrosis took part in the study after giving informed consent. The diagnosis of cystic fibrosis was established on the basis of malabsorption, chronic bronchopulmonary infection, and a sweat sodium concentration of over $70 \mathrm{mmol}(\mathrm{mEq}) / 1$. The mean age of the patients was 22.5 (range 13-37) years. The mean FEV $_{1}$ was 1.3 (range $0.45-3.25$ ) litres and the mean forced vital capacity (FVC) was $2 \cdot 5(1 \cdot 1-5 \cdot 1) 1$.

All patients had been admitted to hospital with an exacerbation of their bronchopulmonary infection and were studied for three consecutive days as near as possible to the date of discharge. To take part in the study, patients were required to be producing at least $20 \mathrm{~g}$ of sputum in 24 hours and needed to be fit enough to carry out their own chest physiotherapy. Patients with pneumothorax or a history of pneumothorax were excluded.

Appropriate gravity assisted positions for postural 
drainage were assessed for each individual before the start of the study. Usually two areas of the chest were treated during each session. All patients were familiar with the forced expiration technique, which consists of one or two forced expirations (huffs) from mid lung volume to low lung volume, followed by a short period of relaxation and breathing control to avoid any increase in airflow obstruction. As the secretions reach the upper airways they are cleared by a huff or cough at high lung volume. ${ }^{2}$

Instructions and practice with the positive expiratory pressure (PEP) equipment were given before the study. The PEP system (Astra Meditec) normally consists of a face mask and a one way valve to which expiratory resistances can be attached. ${ }^{1} \mathrm{~A}$ manometer is inserted into the system to monitor the actual value of PEP. Patients trying this apparatus before our study preferred the use of a mouthpiece and nose clips in place of the face mask, and therefore throughout the study this system was used (fig).

We used a resistance that gave a PEP level of $12-17 \mathrm{~cm} \mathrm{H}_{2} \mathrm{O}$ in mid expiration. To determine which resistance produced this pressure for each individual, the patient sat comfortably with arms resting on a table and was instructed to breath abdominally with only a slightly active expiration. ${ }^{1}$ Each patient practised groups of six breaths trying different resistances until the correct pressure was obtained. The diameters of the appropriate resistances ranged from 2.5 to $3.5 \mathrm{~mm}$.

Three treatment regimens were used: Treatment $A$ In gravity assisted positions, a cycle of four deep inspirations with relaxed expiration, breathing control $^{4}$ (relaxation and gentle abdominal breathing),

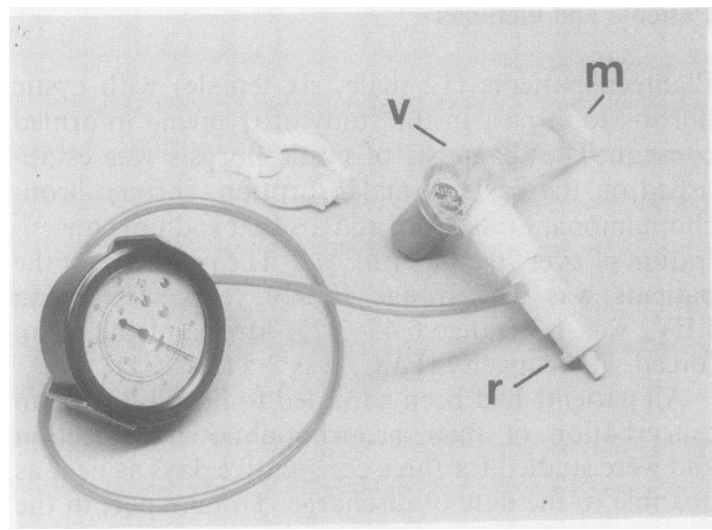

Modified equipment used to achieve positive expiratory pressure. The mouthpiece $(m)$ is connected to a one way valve $(v)$, which causes expiration to be diverted through a resistance $(r)$. Different resistances can be fitted into the expiratory limb of the valve until the desired expiratory pressure is registered by the attached aneroid manometer. and the forced expiration technique; spontaneous coughing as required. Treatment $B$ In gravity assisted positions, a cycle of six breaths with PEP, breathing control, and the forced expiration technique. Spontaneous coughing as required. Treatment $C$ The same technique as in treatment $\mathrm{B}$, but in the sitting position.

Each patient used the three treatment regimens in randomised order over three consecutive days, each regimen being used over a 24 hour period. There were $\vec{x}$ four treatment sessions in each 24 hour period; the three daytime treatments were carried out by the patient himself under the supervision of a phys- $\vec{N}$ iotherapist (JH or BW), and the fourth treatment was $\mathcal{O}$ performed by the patient alone in the evening. The duration of each treatment was established on the $\frac{5}{5}$ first day of the study. It continued until the patient $\vec{\nabla}$ and physiotherapist felt that forced expiration and $\mathbb{D}$ coughing no longer resulted in expectoration of secretions. Bronchodilator drugs were continued before $\bar{\sigma}$ physiotherapy if this was part of the patient's normal $\mathbb{\complement}$ regimen. Fifteen patients were receiving intravenous $\overrightarrow{0}$ antibiotic treatment and three oral antibiotic treat- $\infty$ ment. Recordings were made of $(a)$ weight of sputum during treatment and up to 30 minutes after each treatment (treatment period sputum), a precision balance (Mettler P1200) being used for determining all sputum weights; (b) weight of sputum produced in $\frac{\circ}{\mathbb{Q}}$ the non-treatment periods over each 24 hour period of the study (non-treatment sputum); (c) $\mathrm{FEV}_{1}$ and $\overline{\mathrm{O}}$ FVC recorded with a Vitalograph dry spirometer 3 before and 30 minutes after the first treatment each day and 30 minutes after the third treatment each day; $(d)$ arterial oxygen saturation $\left(\mathrm{SaO}_{2}\right)$, estimated with an ear oximeter (Hewlett-Packard), was recorded for 10 minutes with the patient in a sitting $\underset{-}{\times}$ position before the first treatment each day, through- 3 . out the treatment, and for 30 minutes resting in a sitting position after treatment - the range of values during the resting periods before and after treatment $\mathrm{O}$ and during cycles of breathing exercises, PEP, the forced expiration technique, and coughing all being $\frac{7}{2}$ extracted from the recorded trace.

The sputum weights and $\mathrm{SaO}_{2}$ were subjected to $\sigma$ statistical analysis by means of the Wilcoxon matched $N$ pairs signed ranks test and the $\mathrm{FEV}_{1}$ and FVC by N means of a Friedman two way analysis of variance.

\section{Results}

Table 1 shows the mean weights of sputum produced ${ }_{+}^{+}$ in each 24 hour period. During treatment $A$ a significantly greater quantity of sputum was produced施 than during treatments $B$ and $C$, and treatment $B \frac{P}{\mathbb{Q}}$ produced more sputum than treatment $\mathrm{C}$; but on the days of treatment $\mathrm{C}$ (in the sitting position) 
Table 1 Mean weight of sputum produced in each 24 hour period (range in parentheses)

\begin{tabular}{|c|c|c|c|}
\hline & Treatment sputum (g) & Non-treatment sputum $(\mathrm{g})$ & $\begin{array}{l}\text { Total sputum }(\mathrm{g}) \text { (treatment }+ \\
\text { non-treatment) }\end{array}$ \\
\hline \multicolumn{4}{|l|}{ Treatment A: } \\
\hline $\begin{array}{l}\text { Gravity, B ex, FE } 1 \\
\text { Treatment B: }\end{array}$ & $03.3(29.9-199.8)$ & $16.5(0-51 \cdot 7)$ & $79 \cdot 8(30 \cdot 7-219 \cdot 8)$ \\
\hline Gravity, PEP, FET & $54.5(21.9-210 \cdot 7)$ & $16 \cdot 1(1 \cdot 0-56 \cdot 0)$ & $70 \cdot 6(24 \cdot 7-256 \cdot 8)$ \\
\hline $\begin{array}{l}\text { Treatment C: } \\
\text { Sitting, PEP, FET }\end{array}$ & $42.3(13.9-115.1)$ & $23.8(1.4-74.3)$ & $66.1(15 \cdot 3-189.4)$ \\
\hline $\begin{array}{l}\text { Statistical results } \\
\quad \text { (Wilcoxon matched } \\
\text { pairs signed ranks test) }\end{array}$ & $\begin{array}{l}\text { A higher than B, } p<0.025 \\
\text { A higher than C, } p<0.001 \\
\text { B higher than } \mathrm{C}, \mathrm{p}<0.005\end{array}$ & $\begin{array}{l}\text { A } v \text { B NS } \\
\text { A lower than C, } p<0.05 \\
\text { B lower than C, } p<0.005\end{array}$ & $\begin{array}{l}\text { A higher than B, } \mathrm{p}<0.05 \\
\text { A higher than } \mathrm{C}, \mathrm{p}<0.005 \\
\text { B } v \text { C NS }\end{array}$ \\
\hline
\end{tabular}

B ex--breathing exercises; FET--forced expiration technique; PEP--positive expiratory pressure.

Table 2 Mean $F E V_{1}$ and forced vital capacity (FVC) before and after three forms of chest physiotherapy in 18 patients with cystic fibrosis

\begin{tabular}{|c|c|c|c|}
\hline & $\begin{array}{l}\text { Before } \\
\text { treatment I }\end{array}$ & $\begin{array}{l}30 \mathrm{~min} \\
\text { after } \\
\text { treatment l }\end{array}$ & $\begin{array}{l}30 \mathrm{~min} \\
\text { after } \\
\text { treatment } 3\end{array}$ \\
\hline \multicolumn{4}{|c|}{$\begin{array}{l}\text { Treatment A: } \\
\text { Gravity, B ex, FET }\end{array}$} \\
\hline $\begin{array}{l}\text { FEV } \\
\text { FVC }\end{array}$ & $\begin{array}{l}1.33 \\
2.56\end{array}$ & $\begin{array}{l}1.38 \\
2.65\end{array}$ & $\begin{array}{l}1.37 \\
2.70\end{array}$ \\
\hline \multicolumn{4}{|c|}{$\begin{array}{l}\text { Treatment B: } \\
\text { Gravity, PEP, FET }\end{array}$} \\
\hline $\begin{array}{l}\text { FEV }_{1} \\
\text { FVC }\end{array}$ & $\begin{array}{l}1.35 \\
2.51\end{array}$ & $\begin{array}{l}1.40 \\
2.62\end{array}$ & $\begin{array}{l}1.39 \\
2.62\end{array}$ \\
\hline \multicolumn{4}{|c|}{$\begin{array}{l}\text { Treatment C: } \\
\text { Sitting, PEP, FET }\end{array}$} \\
\hline $\begin{array}{l}\text { FEV }_{1} \\
\text { FVC }\end{array}$ & $\begin{array}{l}1 \cdot 34 \\
2 \cdot 55\end{array}$ & $\begin{array}{l}1 \cdot 39 \\
2.62\end{array}$ & $\begin{array}{l}1.40 \\
2.69\end{array}$ \\
\hline
\end{tabular}

Abbreviations as in table 1.

significantly more sputum was produced in the nontreatment periods of the 24 hours than on the days of treatments A and B (in the gravity assisted drainage positions). The total sputum produced on the days of treatment $A$ was significantly greater than on the days of treatments $\mathrm{C}$ and $\mathrm{B}$. There was no significant difference in total sputum between treatment days $B$ and $C$.

There was no significant difference in $\mathrm{FEV}_{1}$ and FVC before treatment, 30 minutes after treatment 1 , and 30 minutes after treatment 3 each day. When treatment days $\mathrm{A}, \mathrm{B}$, and $\mathrm{C}$ were compared there was no significant improvement or deterioration in $\mathrm{FEV}_{1}$ or FVC with any of the treatments (table 2).

Table 3 shows the means of the lowest and highest points of $\mathrm{SaO}_{2}$ before, during, and after treatments $\mathrm{A}$, $B$, and $C$. There were no significant differences. No individual patient showed a significant difference in oxygen saturation and the mean pretreatment resting values for each patient were similar.

The time for an individual treatment session ranged from 10 to 31 (mean 21) minutes, and total daily treatment time ranged from 59-105 (mean 83) minutes. The minimum time in any one gravity assisted position was 10 minutes.

\section{Discussion}

The forced expiration technique and coughing were used in each treatment regimen in this study. These forced expiratory manoeuvres, depending on dynamic compression of the airways, ${ }^{56}$ probably move secretions centrally from about the seventh generation of bronchi. The gravity assisted positions used in treatments $A$ and $B$ resulted in greater clearance of secretions than treatment $\mathrm{C}$, which was carried out in the sitting position. This finding is supported by Sutton et al, ${ }^{7}$ who used a radioaerosol method and

Table 3 Mean oxygen saturation before, during, and after three forms of physiotherapy in 18 patients with cystic fibrosis (range in parentheses)

\begin{tabular}{|c|c|c|c|c|c|c|}
\hline & \multicolumn{2}{|c|}{ Before treatment } & \multicolumn{2}{|c|}{ During treatment } & \multicolumn{2}{|l|}{ After treatment } \\
\hline & Low & High & Low & High & Low & High \\
\hline $\begin{array}{l}\text { Treatment A: } \\
\text { Gravity, B ex, FET } \\
\text { Treatment B: }\end{array}$ & $87 \cdot 72(63-93)$ & $93 \cdot 33$ (77-96) & $86 \cdot 61(56-95)$ & $95 \cdot 72(89-100)$ & $86.94(60-94)$ & $94.00(84-99)$ \\
\hline $\begin{array}{l}\text { Gravity, PEP, FET } \\
\text { Treatment C: }\end{array}$ & $87 \cdot 39$ (62-98) & $93 \cdot 22(78-99)$ & $86 \cdot 57(58-94)$ & $95 \cdot 50$ (89-99) & $87 \cdot 50(70-93)$ & 94.00 (88-99) \\
\hline Sitting, PEP, FET & $88 \cdot 11(70-95)$ & $93.66(82-100)$ & $87 \cdot 44(66-95)$ & $95 \cdot 72$ (91-99) & $87 \cdot 56$ (64-95) & $94 \cdot 11(84-99)$ \\
\hline
\end{tabular}

Abbreviations as in table 1. 
showed that the forced expiration technique produced significantly more sputum in gravity assisted positions than in the sitting position.

Falk et $a^{1}{ }^{1}$ concluded from their trial that sputum production could be significantly increased by using positive expiratory pressure, but in our study we have shown no advantage of positive expiratory pressure (treatment B) over breathing exercises emphasising inspiration (treatment A). The total sputum produced on the days of treatment $A$ was indeed greater than on the days of treatment $B(p<0.05)$.

Positive expiratory pressure is thought to increase collateral airflow to areas of the lung with airways obstructed by secretions, thus mobilising the more peripheral secretions. Probably a similar effect is produced by breathing exercises emphasising inspiration. The simplest, most immediate method for decreasing resistance to obstructed regions of the lung is to increase lung volume. ${ }^{8}$ This probably allows air to get behind secretions in the small obstructed airways.

A total of four deep breaths in each cycle was used in treatment $A$, so that hyperventilation would be avoided. After the deep breaths, the forced expirations, and coughing, brief pauses for relaxation and gentle controlled breathing were included to avoid both fatigue and an increase in airflow obstruction. Treatment currently used by patients with cystic fibrosis often includes self percussion. This was omitted during the study to avoid introducing another variable factor. This was considered ethically justifiable as a recent study ${ }^{9}$ has shown that self percussion is not an essential part of the treatment provided that the other techniques are carried out effectively.

Falk et al $^{1}$ concluded from their study that positive expiratory pressure used in the sitting position for $\mathbf{2 0}$ minutes was more effective than their "classical treatment." This latter treatment consisted of drainage in seven positions for four to five minutes each, with percussion, but this was not accompanied by deep inspirations. The forced expiration technique was also included. This treatment was found to be tiring, and less effective than treatment with positive expiratory pressure in terms of sputum production; and it caused a fall in transcutaneous oxygen tension. Perhaps because inspiratory breathing exercises during the percussion and pauses for relaxation and breathing control were not included, it compared unfavourably with the positive expiratory pressure treatment in their study, and this could be the reason that we could show no advantage of positive expiratory pressure over our current method of treatment, either in sputum production or in oxygen saturation.
It is important to attempt to clear the airways as efficiently as possible during a treatment so that there is a minimum of coughing in intervening periods that might interfere with daily life. Thus the inconvenience of using gravity assisted positions, instead of sitting, to carry out treatment may be outweighed by the benefits of more effective airway clearance.

Most adolescent and adult patients with cystic fibrosis are able to carry out their treatment independently using gravity assisted positions, breathing exercises emphasising inspiration, and the forced expiration technique. We have shown that secretions were cleared less effectively when patients used positive expiratory pressure both with and without gravity assisted positions.

We are grateful to the Cystic Fibrosis Research Trust for financial support, and to Mrs M Falk and Mrs M Kelstrup for allowing BAW to visit the physiotherapy department and cystic fibrosis unit at Rigshospitalet, Copenhagen. We would also like to thank Dr J C Batten for permission to study his patients, $\mathrm{Dr} \mathrm{E}$ Sawicka for her advice, and Miss M Rehahn for the statistical analyses.

\section{References}

1 Falk M, Kelstrup M, Andersen JB, et al. Improving the ketchup bottle method with positive expiratory pressure, PEP, in cystic fibrosis. Eur J Respir Dis 1984;65:423-32.

2 Pryor JA, Webber BA. An evaluation of the forced expiration technique as an adjunct to postural drainage. Physiotherapy 1979;65:304-7.

3 Pryor JA, Webber BA, Hodson ME, Batten JC. Evaluation of the forced expiration technique as an adjunct to postural drainage in treatment of cystic fibrosis. Br Med J 1979;ii:417-8.

4 Gaskell DV, Webber BA. Brompton Hospital guide to chest physiotherapy. 4th ed. Oxford: Blackwell Scientific Publications, 1980:13.

5 Leith D. Cough. Physical Therapy 1968;48:439-47.

6 Sutton PP, Pavia D, Bateman JRM, Clarke SW. Chest physiotherapy: a review. Eur J Respir Dis 1982;63: 188-201.

7 Sutton PP, Parker RA, Webber BA, et al. Assessment of the forced expiration technique, postural drainage and directed coughing in chest physiotherapy. Eur J Respir Dis 1983;64:62-8.

8 Menkes H, Britt J. Rationale for physical therapy. Am Rev Respir Dis 1980;122(suppl Nov, part 2):127-31.

9 Webber BA, Parker RA, Hofmeyr JL, Hodson ME. Evaluation of self-percussion during postural drainage using the forced expiration technique. Physiotherapy Practice 1985;1:42-5. 